\title{
Determinants of Outcomes and Prognosis Score in Obstetric Vesico-Vaginal Fistula Repair
}

\author{
Leon Mubikayi1 ${ }^{*}$, David O. Matson ${ }^{2,3}$, Vicky Lokomba4, Justin Mboloko4, Jean Patrick Kamba4, \\ Rahma Tozin 4
}

${ }^{1}$ School of Medicine, Kasayi University, Kananga, Democratic Republic of the Congo (DRC)

${ }^{2}$ Graduate Program in Public Health, Eastern Medical School, Norfolk, USA

${ }^{3}$ Department of Pediatrics, Eastern Virginia Medical School, Norfolk, USA

${ }^{4}$ School of Medicine, University of Kinshasa, Kinshasa, Democratic Republic of the Congo (DRC)

Email: *leonmubik@yahoo.fr

How to cite this paper: Mubikayi, L., Matson, D.O., Lokomba, V., Mboloko, J., Kamba, J.P. and Tozin, R. (2017) Determinants of Outcomes and Prognosis Score in Obstetric Vesico-Vaginal Fistula Repair. Open Journal of Obstetrics and Gynecology, 7, 767-777. https://doi.org/10.4236/ojog.2017.77078

Received: May 4, 2017

Accepted: July 28, 2017

Published: July 31, 2017

Copyright (c) 2017 by authors and Scientific Research Publishing Inc. This work is licensed under the Creative Commons Attribution International License (CC BY 4.0).

http://creativecommons.org/licenses/by/4.0/

\begin{abstract}
An estimated 2 million women living in countries with limited resources currently have vesico-vaginal, recto-vaginal, or mixed types of fistulae because of the necrosis that occurs with obstructed labor. We evaluated factors readily assessed by the examining practitioner in a consecutive case series of surgical repairs of obstetrical fistulae, for the ability of those factors to stand as a prognostic guide, in a clinical score. Objectives: To identify the predictors of surgical repair outcomes and establish a Score combining these different determinants to facilitate the care of obstetric fistula. Methods: We conducted a multicentric prospective study between 2011 and 2014 in Democratic Republic of the Congo (DRC). Outcomes: We measured 3 months post-surgery in a series of 483 patients with obstetrical fistula repaired by the same surgeon included closure and failure appreciated by dye test. Multivariable generalized estimating equation models were used to generate adjusted odd ratios (OR) and 95\% confidence intervals (CIs). The scores ranging from 3 to 14 were established from the outcomes determinants identified. Results: In total, 483 women were enrolled, and 390 cases were at their first surgery and were included in the obstetric fistula (OF) prognosis score and classification. Their mean age was 35 years at the time of the surgery and 25 years at the onset of OF. In $28.6 \%$, the fistula patient was primigravida. Mean duration between onset of the fistula and surgical treatment was 8 years. In $24 \%$, the fistula patients lived separated from their partners. Overall closure rate of the fistulas was $85.7 \%$. Severe vaginal fibrosis $(p<0.01)$, big fistula size $(<0.01)$, small distance from fistula to external urethral meatus $(<0.01)$ and prior surgery $(\mathrm{p}$ $<0.48$ ) predicted failed fistula closure. A clinical score ranging from 3 to 14 points is a prognostic score with a range of 1 to 4 for the distance between the fistula and the external meatus and the size, and a scale of 1 to 6 for fibrosis.
\end{abstract}


Conclusions: This study demonstrated that the marked vaginal scarring; large fistula size and distance to urethral meatus are predictors for unsuccessful fistula repair. Due to the lack of a standard classification that is never unanimous among the different surgeons, this prognostic score allows the combination of the different determinants assessing the chances of success and can help the practitioners to orient the patients towards the determined skill scale to take care of the patients.

\section{Keywords}

Obstetrical Fistula, Repair, Outcomes, Prognosis Score

\section{Introduction}

Vesico-vaginal fistula (VVF) is an abnormal communication between the vagina and the bladder. It can have traumatic, accidental, carcinomatous, radic and obstetric causes. The latter accounts for more than $90 \%$ of the cases [1] [2] [3] [4].

The obstetric FVV is due to uncorrected obstructed labor in time [5] [6].

The direct consequences of this situation include urinary and/or fecal incontinence in cases where the rectum is involved. Rectovaginal fistulas (RVFs) also occur because of unrepaired perineal lacerations. Additional complications of obstructed labor may include uterine rupture, amenorrhea and secondary infertility, and foot drop [7].

It is estimated that over 2 million women in countries with limited resources living with vesico-vaginal fistula (VVF) or recto vaginal (RVF), first as a result of prolonged obstructed labor [4].

It should be noted that in the DRC, obstetric fistula is a real public health problem. The annual incidence has been estimated at about 7000 cases and an average of 400 cases are repaired per year, with the support of the various partners of the Government [8].

The treatment of obstetric fistula is essentially surgical and its cure rate varies between $80 \%$ and $90 \%$ in the hands of the experienced surgeon [9].

This treatment depends on the complexity of the case, which is often appreciated by the different classifications. These different classifications take into account the anatomy and quality of the tissues appreciated by the degree of fibrosis and the size of the fistula. These elements are very subjective and sometimes confuse the surgeon: A large fistula from the neck of the bladder to the cervix can be considered supra-urethral for one surgeon and supra-cervical for the other. The same fistula can be considered complex by a less experienced surgeon and simple one by a more experienced one. These different classifications do not have the same definitions, thus making the comparison of the different results very difficult [10].

To overcome these difficulties, we have initiated this work, the objectives of which are to identify the epidemiological profile of women with obstetric fistula, identify the determinants of the success of surgical repair and establish a Score 
combining these different determinants to facilitate the care of these women victims of obstetric fistula.

\section{Materials and Methods}

All the women seeking fistula repair services between January 2011 and December 2014 were recruited for this prospective cohort study at five sites in the Democratic Republic of the Congo (DRC), including two sites in the south of DRC, the former Katanga province (Kabongo and Kolwesi), two sites in the center of the country in the former Eastern Kasai province (Lodja and Kole) and one site in the capital city Kinshasa. These centers, except the Biamba Marie Mutombo Hospital in Kinshasa, benefited from visits by the surgical team in outreach.

We looked at demographic variables such as the age of the patient, parity, provenance, level of education, marital status and qualification of the birth attendant (Table 1).

Clinical data include characteristics of obstetric fistula such as size, distance between the lower fistula border and the external urethral meatus portal, fibrosis, anterior repair and fistula type (Table 2).

The fistula size and distance from fistula to urethral meatus were expressed in centimeters $(\mathrm{cm})$.

The size was classified in $1-2 \mathrm{~cm}, 3-4 \mathrm{~cm}$ and more than $4 \mathrm{~cm}$, while the distance from the lower edge of the fistula to the external orifice of the urethral meatus was classified as $1-2 \mathrm{~cm}, 3 \mathrm{~cm}$ and more than $3 \mathrm{~cm}$, the reference being the bladder sphincter located at $3 \mathrm{~cm}$ from the external orifice of the urethral meatus in woman.

Fibrosis expresses the degree of tissue rigidity appreciated by the clinician or anatomopathology and is expressed in mild, moderate and severe as the case may be. Patients with mild fibrosis have soft tissues, those with moderate fibrosis have mild mobility, and those with severe fibrosis have rigid tissues that are difficult to mobilize.

Factors noted at the time of the pre-surgical evaluation that were statistically independent among the case series of 483 distinct patients were degree of fibrosis, size of the fistula, distance of the fistula from the urethral opening and prior surgery intended to repair the obstetrical fistula. Since prior surgery is expressed in clinic by fibrosis level, this variable was not used in this score to facilitate the understanding. So, we are going to consider only the patients who underwent the first surgery performed by the one surgeon in this score to avoid confusion bias $(n=390)$.

Degree of fibrosis categorized prior to surgery was confirmed $(r=0.97)$ by biopsy specimens obtained during surgery $(n=118$ patients).

The margin for observing an effect of the fistula upon ultimate function of the urethral sphincter was at $3 \mathrm{~cm}$. All patients whose fistula was $2 \mathrm{~cm}$ or fewer from the urethral opening had a physiological compromise of the urethral sphincter.

The number $(n=5)$ of patients with vaginal-rectal fistula or with both a vesicovaginal and recto-vaginal fistula, i.e., "mixed" obstetric fistulae, $(n=8)$ was too 
small to be included in this study. A larger number of cases of recto-vaginal fistula and of mixed obstetric fistulae will be needed to exam effects of, for example, fistula distance from the anal sphincter upon fecal continence and mixed fistula on success of obtaining urethral continence.

Table 1. Attributes of patients in this case series of patients with surgery for repair of obstetric fistula.

\begin{tabular}{|c|c|c|c|c|}
\hline Attribute & \multicolumn{4}{|c|}{ Distribution among Cases } \\
\hline \multicolumn{5}{|l|}{ Age (median, range, standard deviation) } \\
\hline At marriage & \multicolumn{4}{|c|}{18 years, 13 to 46 years, 6.5 years } \\
\hline At occurrence of obstetric fistula & \multicolumn{4}{|c|}{25 years, 14 to 50 years, 6.9 years } \\
\hline At surgery in this case series & \multicolumn{4}{|c|}{35 years, 16 to 76 years, 10.7 years } \\
\hline Years with obstetric fistula & \multicolumn{4}{|c|}{8 years, 4 to 61 years, 9.6 years } \\
\hline Duration of labor & \multicolumn{4}{|c|}{3.0 days, 1 to 5 days, 0.86 days } \\
\hline Distance to delivery site & \multicolumn{4}{|c|}{$4.0 \mathrm{Km}, 1$ to $30 \mathrm{Km}, 3.1 \mathrm{Km}$} \\
\hline \multirow[t]{5}{*}{ Parity at surgery } & \multicolumn{2}{|c|}{ Number } & \multicolumn{2}{|c|}{ Frequency (\%) } \\
\hline & \multicolumn{2}{|c|}{ Primigravida $(\mathrm{n}=1)$} & \multicolumn{2}{|c|}{$138(28.6)$} \\
\hline & \multicolumn{2}{|c|}{ Paucigravida $(\mathrm{n}=2$ or 3 ) } & \multicolumn{2}{|c|}{$212(43.9)$} \\
\hline & \multicolumn{2}{|c|}{ Multigravida ( $\mathrm{n}=4$ or 5 ) } & \multicolumn{2}{|c|}{$76(13.7)$} \\
\hline & \multicolumn{2}{|c|}{ Grand multigravida $(\mathrm{n} \geq 6)$} & \multicolumn{2}{|c|}{$57(11.8)$} \\
\hline \multirow[t]{5}{*}{ Patient Education } & \multicolumn{2}{|c|}{ Level Attained } & \multicolumn{2}{|c|}{ Frequency (\%) } \\
\hline & \multicolumn{2}{|c|}{ None } & \multicolumn{2}{|c|}{$143(29.6)$} \\
\hline & \multicolumn{2}{|c|}{ Primary } & \multicolumn{2}{|c|}{$195(40.4)$} \\
\hline & \multicolumn{2}{|c|}{ Secondary } & \multicolumn{2}{|c|}{$141(29.2)$} \\
\hline & \multicolumn{2}{|c|}{ University } & \multicolumn{2}{|c|}{$4(0.8)$} \\
\hline Marital Status & & Status & Freq & cy $(\%)$ \\
\hline & & vorced & & 5.0) \\
\hline & & Iarried & & 61.5) \\
\hline & & tranged & & 7.2) \\
\hline & & Single & & 26.3) \\
\hline Delivery Attendant & & tendant & Freq & cy $(\%)$ \\
\hline & & Nurse & & 27.5) \\
\hline & & ysician & & 61.7) \\
\hline & Traditio & nal attendant & & $0.8)$ \\
\hline Statistically independent factors & ociated with s & urgical and functic & al outco & \\
\hline Variable & Coefficient & Standard Error & F-test & p-Value \\
\hline Greater degree of fibrosis & 0.43 & 0.03 & 183.6 & $<0.001$ \\
\hline Larger fistula size $(\mathrm{cm})$ & -0.17 & 0.02 & 83.6 & $<0.001$ \\
\hline Distance $(\mathrm{cm})$ of fistula from urethra & 0.10 & 0.02 & 39.0 & $<0.001$ \\
\hline Previous surgery for repair of fistula & $-0.13^{*}$ & 0.06 & 3.9 & 0.048 \\
\hline
\end{tabular}

Correlation Coefficient: $\mathrm{r}^{2}=0.50$, with these four variables

${ }^{\star} 1=$ Yes, $0=$ No. 
Table 2. Outcomes of Obstetric Fistula Repair According to Single Factors Noted at PreSurgical Evaluation in a Case Series of 483 Patients.

\begin{tabular}{|c|c|c|c|}
\hline \multirow{2}{*}{ Attribute of Fistula } & \multirow{2}{*}{$\%(\mathrm{~N})$ Among Cases } & \multicolumn{2}{|c|}{ Outcome of Surgery [\% $(\mathrm{N})$ for Row } \\
\hline & & Closed & Not Closed \\
\hline \multicolumn{4}{|l|}{ Fibrosis } \\
\hline None & $60.9(294)$ & $97.6(287)$ & $2.4(7)$ \\
\hline Mild & $21.5(104)$ & $86.5(90)$ & $13.5(14)$ \\
\hline Severe & $17.6(85)$ & $40.0(34)$ & $60.0(51)$ \\
\hline Total & $100.0(483)$ & $85.1(411)$ & $14.9(72)$ \\
\hline \multicolumn{4}{|l|}{ Size } \\
\hline $1 \mathrm{~cm}$ & $25.3(122)$ & $96.7(118)$ & $3.3(4)$ \\
\hline 2 & $34.0(169)$ & $92.9(157)$ & $7.1(12)$ \\
\hline 3 & $18.8(91)$ & $80.2(73)$ & $19.8(18)$ \\
\hline 4 & $14.9(72)$ & $73.6(53)$ & $26.4(19)$ \\
\hline 5 & $2.9(14)$ & $50.0(7)$ & $50.0(7)$ \\
\hline 6 & $3.1(15)$ & $20.0(3)$ & $80.0(12)$ \\
\hline Total & $100.0(483)$ & $85.1(411)$ & $14.9(72)$ \\
\hline \multicolumn{4}{|l|}{ Distance to Urethra } \\
\hline $0 \mathrm{~cm}$ & $1.2(6)$ & $33.3(2)$ & $66.7(4)$ \\
\hline 1 & $1.2(6)$ & $16.7(1)$ & $83.3(5)$ \\
\hline 2 & $3.9(19)$ & $26.3(5)$ & $73.7(14)$ \\
\hline 3 & $7.9(38)$ & $63.2(24)$ & $36.8(14)$ \\
\hline 4 & $24.4(118)$ & 90.7 (107) & $9.3(11)$ \\
\hline 5 & $22.2(107)$ & $90.7(97)$ & $9.4(10)$ \\
\hline 6 & $22.0(106)$ & $94.3(100)$ & $5.7(6)$ \\
\hline 7 & $12.6(61)$ & $88.5(54)$ & $11.5(7)$ \\
\hline 8 & $4.6(22)$ & $95.5(21)$ & $4.6(1)$ \\
\hline Total & $100.0(483)$ & $85.1(411)$ & $14.9(72)$ \\
\hline \multicolumn{4}{|c|}{ Previous Surgery for Repair } \\
\hline No & $16.6(80)$ & $100.0(80)$ & $0.0(0)$ \\
\hline Yes & $83.4(403)$ & $82.1(331)$ & $17.9(72)$ \\
\hline Total & $100.0(483)$ & $82.6(399)$ & $14.9(72)$ \\
\hline
\end{tabular}

All the patients were operated under spinal anesthesia and vaginally. The best exposure of the surgical field was obtained by: 1) position of lithotomy and trendelburg, 2) retraction of the vulva by suturing of labia minora and lax lower vagina with labia majora helps in exposing the surgical site, 3) placing of a $\mathrm{Au}$ ward speculum. In the case of severe vaginal stenosis, one or two discharge incisions were sometimes necessary. An incision around the fistula, followed by a large dissection under hemostasis control, allowed the vaginal wall to be separated from the bladder wall to allow the bladder to suture without tension (a necessary condition for healing).

The bladder was closed in two planes, the first in separate points with vicryl 2 - 0 followed by an overlaying vicryl 3 - 0 and the vagina with vicryl $2-0$. For pa- 
ra cervical localization, the ureters were identified and catheterized before surgery. A bladder foley catheter was left in place for 10 to 14 days depending on the complexity of the case. Patients were encouraged to drink enough after surgery. Patients were evaluated at discharge from the hospital, 2 weeks and three months later. This evaluation consisted to test with dye test if the fistula was closed or not.

At the third month control, patients were classified according to whether the fistula was closed and dry, closed and not dry (residual incontinence) and not closed (failure). Closed means no fistula opening upon surgeon physical examination; if doubt, dye test was performed and dry means woman is continent for urine upon injection of methylene blue in the bladder (dye test).

Statistical analysis by Epi Info allowed us to combine the different characteristics of the fistula to have a clinical score that can help the clinician establish the prognosis score for the success of surgical repair (Appendix: Table S1).

From the Epi info analysis, the scale of the different fistula characteristics in fistula outcome repair was established. Each fistula characteristic was associated with the score ant the total score helped us to get the prognosis score which will help practitioners to make good decision for their patients.

A score ranging from 3 to 14 points is a prognostic score with a range of 1 to 4 for the distance between the fistula and the urethral meatus and the size, and a scale of 1 to 6 for fibrosis (Appendix Table).

From the adjusted OR, distance was coted: more than $3 \mathrm{~cm}=1,3 \mathrm{~cm}=2$ and less than $3 \mathrm{~cm}=4$. Size was coted: $0-2 \mathrm{~cm}=1,3-4 \mathrm{~cm}=2$ and more than $4 \mathrm{~cm}$ $=4$ and for the fibrosis: mild $=1$, moderate $=3$ and severe $=6$.

\section{Results}

In this study with 483 obstetric fistulae patients, 470 cases were vesico-vaginal fistulae, $97.3 \%$ and 13 mixed vesico-vaginal and recto-vaginal fistula blisters, or $2.7 \%$ (Figure 1). Of these $470 \mathrm{FVVs}, 403$ fistulas were closed (85.7\%) and 67 were reported as failure (14.3\%). Of 13 mixed fistulas, 8 were closed (61.5\%) and $5(38.5 \%)$ were reported as failure.

At the time of surgery, the average age of our patients was 35 years (Table 1) ranging between 16 and 76 years. The average age of entry into marriage was 18 years with the variation ranging from 13 to 46 years and fistula appeared in these patients at the mean age of 25 years with the variation ranging from 14 to 50 years, the mean life with fistula was 8 years with variations between 4 months to 61 years. The average duration of the index delivery labor that resulted in the formation of the obstetric fistula was 3 days with variations from 12 to 5 days. One-third of these women were illiterate, $61.5 \%$ were married. The average parity of these women at the time of surgery was 4 children, range 1 and 11 .

Married women accounted for $61 \%$ of cases and single women $26 \%$. Most deliveries during fistula occurred by a health worker, $27.5 \%$ by a nurse and $61.7 \%$ by a physician. It should be noted that $10.8 \%$ of deliveries were provided by a traditional birth attendant. 


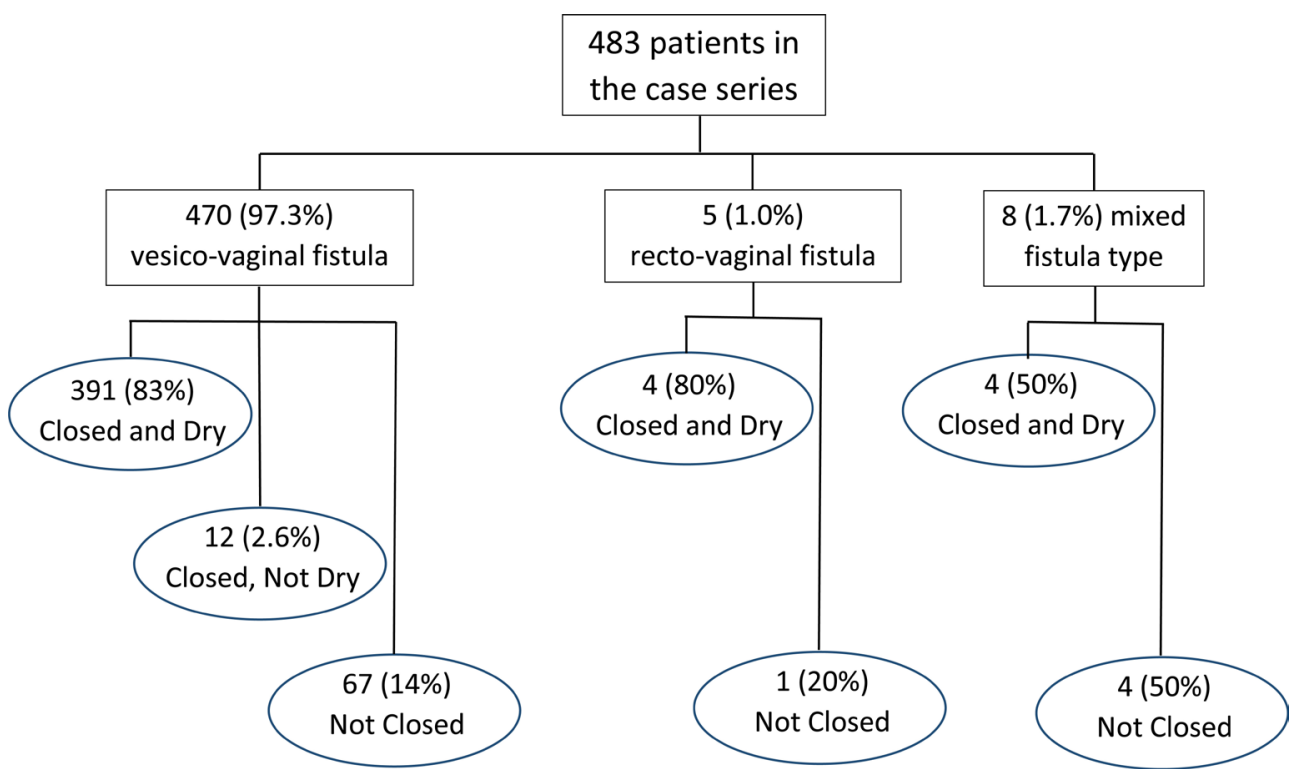

Figure 1. A total of 483 patients were included in the case series. They were serially enrolled and none were excluded. Most (97\%) had a vesico-vaginal (VV) fistula. Of the women with VV fistula, 391 (83\%) had a Closed and Dry surgical outcome, 12 (2.6\%) had a Closed, Not Dry surgical outcome, and 67 (14\%) had a Not Closed surgical outcome. Among the 5 women undergoing surgical repair of a recto-vaginal (RV) fistula, 4 (80\%) had a Closed and Dry surgical outcome and 1 (20\%) had a Not Closed surgical outcome. For the 8 women undergoing surgery for repair of mixed (VV and RV fistulae), 4 (50\%) had a Closed and Dry surgical outcome and 4 (50\%) had a Not Closed surgical outcome.

The analysis showed the influence of different anatomic fistula characteristics in the post-surgical repair outcome. Severe fibrosis, big size, small distance the urethral meatus and the previous surgery were associated with poor outcome after fistula surgical repair (Table 2).

Multivariate analysis revealed four factors influencing the success of obstetric fistula surgery: vaginal fibrosis $(\mathrm{p}<0.001)$, fistula size $(\mathrm{p}<0.001)$, distance between its lower edge and the external urethral meatus $(\mathrm{p}<0.01)$ and the antecedent of fistula surgery $(\mathrm{p}=0.048)$.

The overall success after surgical repair of obstetric fistula was $85.1 \%$ with a residual incontinence rate of $2.5 \%$ and a failure rate of $14.9 \%$ (Table 3).

This rate is higher in the case of mild fibrosis (97.6\%), the fistula size of one to two centimeters (95\%) and a distance greater than 3 centimeters (91.5\%).

This score showed that if the total is 3 to 5 , it is a simple fistula or type I, the healing prognosis is better, greater than $90 \%$. If the total is between 6 and 8 , it is type 2 or complicated fistula, a prognosis is good and the cure rate is between 50 and $90 \%$ and if the score is greater than 8 , type 3 or complex fistula, the fistula had the poor prognosis and the rate OF healing is less than $50 \%$.

\section{Discussion}

In our series of 483 patients, $2.7 \%$ of the patients had mixed fistulas combining vesico-vaginal fistula with recto-vaginal fistula. This rate varies between $2.2 \%$ and $4 \%$ according to authors throughout the world [5] [7] [11]. The average age 
Table 3. Outcomes of first obstetric fistula repair according to single factors noted and assigned prognostic score for pre-surgical evaluation surgical.

\begin{tabular}{|c|c|c|c|c|c|}
\hline \multirow{2}{*}{ Attribute of Fistula } & \multirow{2}{*}{390 Cases } & \multicolumn{2}{|c|}{$\underline{\text { Closure (\%) }}$} & \multirow{2}{*}{ OR $(95 \% \mathrm{CL})^{*}$} & \multirow{2}{*}{ Prognostic Score } \\
\hline & & Yes & No & & \\
\hline \multicolumn{6}{|l|}{$\underline{\text { Fibrosis }}$} \\
\hline None & 226 & 96.9 & 3.1 & $1.0(-)$ & 1 \\
\hline Mild & 88 & 84.1 & 15.9 & $2.6(2.3,3.70)$ & 3 \\
\hline Severe & 76 & 39.5 & 63.2 & $5.6(3.29,6.72)$ & 6 \\
\hline \multicolumn{6}{|l|}{$\underline{\text { Size }(\mathrm{cm})}$} \\
\hline 1 to 2 & 229 & 93.4 & 19.7 & $1.0(-)$ & 1 \\
\hline 3 to 4 & 133 & 74.4 & 25.6 & $2(1.7,5.2)$ & 2 \\
\hline 5 to 6 & 28 & 35.7 & 64.3 & $4(1.94,8.4)$ & 4 \\
\hline \multicolumn{6}{|l|}{ Distance $(\mathrm{cm})$ to Urethra } \\
\hline$>3$ & 330 & 90.3 & 9.7 & $1.0(-)$ & 1 \\
\hline 3 & 30 & 56.7 & 43.3 & $2.36(1.77,3.12)$ & 2 \\
\hline 0 to 2 & 30 & 26.7 & 73.3 & $4(3.62,6.21)$ & 4 \\
\hline
\end{tabular}

*“OR" = odds ratio; "95\% CL" = 95\% confidence limits for OR. \#p Values for all comparisons are $\mathrm{p}<0.001$.

at the time of surgery is 35 years (16 - 76 years) in our series. The age observed in our series is close to that found by Yeakey and al. [12] in Malawi, Tegbeu [13] in Cameroon (37 years old) and Arshad [14] in Tunisia (35.5 years old). However, this age varies between 25 and 30 years for most authors around the world [4] [6] [9] [15]. This age depends on the availability of surgeons in the area. The average age at onset of fistula was 25 years and the average length of time our patients had fistula was 8 years (4 months to 61 years) due to lack of availability of surgeons, 2 to 4 years for most authors around the world [5] [7] [9] [16] except Tegbeu who found 8.5 years in Cameroon.

The duration of the index delivery labor that resulted in the formation of the obstetric fistula was 3 days as most authors have also noted in their series [9] [16] [17]. The average parity of these patients was 4 children per woman. This parity is superior to that found by Barone in his study on 5 sites in 4 countries [2], the difference being due to the fact that in our series $61.5 \%$ of women still remained in their marriages despite the presence of fistula and had the children before their repair.

Multivariate linear regression showed that fibrosis, size of the fistula, distance from the lower edge of the fistula to the external urethral orifice, and previous surgery were as the determinants of obstetric fistula healing (Table 2). Among these determinants, fibrosis and urethral involvement have been identified by other authors [4] [9] [18], although some authors such as Barone [4] and Browing [19] do not recognize the importance of fistula size among the determinants of the success of the cure, however they agree on the size of the bladder, consequence of the size of the latter as an important element in this cure.

Multivariate analysis resulted in the development of this score, which can en- 
able us to orient patients according to the level of competence of the surgeons by classifying them into simple, complicated and complex fistulas according to the severity of the determinants involved.

Since the anterior repair acts via fibrosis, it has been eliminated from this score to facilitate understanding.

Due to the lack of a standard classification that is never unanimous among the different surgeons, our results may help surgeons to make decisions about the skill level needed to repair individual patients as well as to communicate adequately to patients with fistula about the possibility of a failed repair given the characteristic of their fistula. They also provide evidence to support inclusion of certain fistula characteristics, particularly vaginal scarring, distance from fistula to urethral meatus and fistula size in prognostic classification systems. This prognosis score allows the combination of these different determinants to assess the chances of success.

Additional cohort studies that are adequately powered to test hypotheses of effect modification are warranted to confirm whether this prognosis score is indeed beneficial for certain patient populations and surgeons.

\section{References}

[1] UNFPA, USAID (2009) Thematic Evaluation of Programmes and UNFPA Experiences in the "Campaign to End Fistula" Debriefing Meeting. UNFPA, New York, 22.

[2] Mohsen, Y. (2006) Prognostic Factors of Recurrence after Vesicovaginal Fistula Repair. International Journal of Urology, 13, 345-349. https://doi.org/10.1111/j.1442-2042.2006.01308.x

[3] Ibrahim, T., Sadio, A.V. and Daniel, S.O. (2000) Characteristics of VVF Patients as Seen at the Specialist Hospital. West African Journal of Medicine, 36, 19.

[4] Barone, M.A., Frajzyngier, V. and Ruminjo, J. (2012) Factors Influencing Urinary Repair Outcomes in Developing Countries: A Systemic Review. American Journal of Obstetrics and Gynecology, 207, 248-258. https://doi.org/10.1016/j.ajog.2012.02.006

[5] Raasen, T., Verdaasdonk, E. and Vierhout, M. (2008) Prospective Results after First Time Surgery for Obstetric Fistulas in East African Women. International Urogynecology Journal, 19, 73-79. https://doi.org/10.1007/s00192-007-0389-6

[6] Frajzyngier, V., Ruminjo, J., Asiimwe, F., Barry, T., Bello, A., Danladi, D., Ganda, S., Idris, S., Inoussa, M., Lynch, M., Mussell, F., Podder, D. and Barone, M. (2012) Factors Influencing Choice of Surgical Route of Repair of Genitourinary Fistula, And the Influence of Route of Repair on Surgical Outcomes: Findings from a Prospective Cohort Study. Journal of Obstetrics and Gynaecology, 111, 1344-1353. https://doi.org/10.1111/j.1471-0528.2012.03461.x

[7] Amreen, H., Khaliah, J., Carol, A., Joelle, O., Clifford, R., Kibreab, A., Abrehet, G. and Mary, L. (2005) Surgical Management of Complex Obstetric Fistula in Eritrea. Journal of Women's Health, 14, 839-844. https://doi.org/10.1089/jwh.2005.14.839

[8] Mubikayi, L., Chow, J.E., Matson, O.D., Nzau, E. and Tandu, B. (2016) A CaseConrol Study on Obstetric Fistula Risk Factors in the Democratic Republic of the Congo. Open Journal of Obstetrics and Gynecology, 6, 740-753.

https://doi.org/10.4236/ojog.2016.612092 
[9] Kirschner, C.V., Yost, K., Du, H., Karshima, J., Arrowsmith, S. and Wall, L. (2010) Obstetric Fistula: The ECWA Evangel VVF Center Surgical Experience from Jos, Nigeria. International Urogynecology Journal, 21, 1525-1533. https://doi.org/10.1007/s00192-010-1231-0

[10] Goh, J.T.W. (2004) A New Classification for Female Genital Tract Fistula. Obstetrics and Gynaecology Jobs, 44, 502-504. https://doi.org/10.1111/j.1479-828X.2004.00315.x

[11] Lesley, H.L., Spitzer, R., Deb, A., Leah, J. and Mabeya, H. (2013) Characteristics and Surgical Success of Patients Presenting for Repair of Obstetric Fistula in Western Kenya. International Journal of Gynecology \& Obstetrics, 120, 178-182. https://doi.org/10.1016/j.ijgo.2012.08.014

[12] Yeakey, M., Chipeta, E., Rijken, Y., Taulo, F. and Tsui, A. (2011) Experiences with Fistula Repair Surgery among Women and Families in Malawi. Global Public Health, 6, 153-167. https://doi.org/10.1080/17441692.2010.491833

[13] Tebeu, P., Fomulu, J., Mbassi, A., Tcheliebou, J., Doh, A. and Rochat, C. (2010) Quality Care in Vesico-Vaginal Obstetric Fistula: Case Series Report from the Regional Hospital of Maroua-Cameroon. The Pan African Medical Journal, 34, 6. https://doi.org/10.4314/pamj.v5i1.56192

[14] Karateke, A., Cam, C., Ozdemir, A., Guney, B., Vatansever, D. and Celik, C. (2010) Characteristics of Obstetric Fistulas and the Need for a Prognostic Classification System. Archives of Medical Science, 2, 254-256. https://doi.org/10.5114/aoms.2010.13904

[15] Nardos, R., Menber, B. and Browning, A. (2012) Outcome of Obstetric Fistula Repair after 10-Day versus 14-Day Foley Catheterization. International Journal of Gynecology \& Obstetrics, 118, 21-33. https://doi.org/10.1016/j.ijgo.2012.01.024

[16] Browning, A. (2007) The Circumferential Obstetric Fistula: Characteristics, Management and Outcomes. Journal of Obstetrics and Gynaecology Canada, 114, 1172-1176.

[17] Nardos, R., Browning, A. and Chen, C. (2009) Risk Factors that Predict Failure after Vaginal Repair of Obstetric Vesicovaginal Fistulae. American Journal of Obstetrics \& Gynecology, 200, 1-4. https://doi.org/10.1016/j.ajog.2008.12.008

[18] Browning, A. (2004) Prevention of Residual Urinary Incontinence Following Successful Repair of Obstetric Vesicovaginal Fistula Using a Fibromascular Sling. Journal of Obstetrics and Gynaecology Research, 111, 357-361.

[19] Browning, A. (2006) Risk Factors for Developing Residual Urinary Incontinence after Obstetric Fistula Repair. Journal of Obstetrics and Gynaecology Research, 113, 482-485. https://doi.org/10.1111/j.1471-0528.2006.00875.x 


\section{Appendix}

Table S1. Outcomes of first surgical repair of vaginal-vesicular obstetrical fistula, according to prognostic score assigned for pre-surgical evaluation pre-surgical scoring.

\begin{tabular}{|c|c|c|c|c|c|c|c|c|c|}
\hline \multirow{2}{*}{ Fibrosis } & \multirow{2}{*}{$\begin{array}{l}\text { Fibrosis } \\
\text { Score }\end{array}$} & \multirow{2}{*}{ Size $(\mathrm{cm})$} & \multirow{2}{*}{$\begin{array}{l}\text { Size } \\
\text { Score }\end{array}$} & \multirow{2}{*}{$\begin{array}{c}\text { Distance }(\mathrm{cm}) \\
\text { to Urethra }\end{array}$} & \multirow{2}{*}{$\begin{array}{l}\text { Distance } \\
\text { Score }\end{array}$} & \multirow{2}{*}{$\begin{array}{l}\text { Total } \\
\text { Score }\end{array}$} & \multirow{2}{*}{$\begin{array}{l}\text { Cases }(n=390) \\
\text { in Subgroup }\end{array}$} & \multicolumn{2}{|c|}{ Surgical Closure (\%) } \\
\hline & & & & & & & & Yes & No \\
\hline None & 1 & 1 to 2 & 1 & $>3$ & 1 & 3 & 128 & 99.2 & 0.8 \\
\hline None & 1 & 1 to 2 & 1 & 3 & 2 & 4 & 11 & 90.9 & 9.1 \\
\hline None & 1 & 1 to 2 & 1 & $<3$ & 4 & 6 & 2 & 100.0 & 0.0 \\
\hline None & 1 & 3 to 4 & 2 & $>3$ & 1 & 4 & 72 & 100.0 & 0.0 \\
\hline None & 1 & 3 to 4 & 2 & 3 & 2 & 5 & 1 & 100.0 & 0.0 \\
\hline None & 1 & 3 to 4 & 2 & $<3$ & 4 & 7 & 0 & 0.0 & 0.0 \\
\hline None & 1 & $>4$ & 4 & $>3$ & 1 & 6 & 9 & 77.8 & 22.2 \\
\hline None & 1 & $>4$ & 4 & 3 & 2 & 7 & 1 & 100.0 & 0.0 \\
\hline None & 1 & $>4$ & 4 & $<3$ & 4 & 9 & 1 & 0.0 & 100.0 \\
\hline Mild & 3 & 1 to 2 & 1 & $>3$ & 1 & 5 & 52 & 90.4 & 9.6 \\
\hline Mild & 3 & 1 to 2 & 1 & 3 & 2 & 6 & 4 & 100.0 & 0.0 \\
\hline Mild & 3 & 1 to 2 & 1 & $<3$ & 4 & 8 & 5 & 60.0 & 40.0 \\
\hline Mild & 3 & 3 to 4 & 2 & $>3$ & 1 & 6 & 20 & 85.0 & 15.0 \\
\hline Mild & 3 & 3 to 4 & 2 & 3 & 2 & 8 & 1 & 100.0 & 0.0 \\
\hline Mild & 3 & 3 to 4 & 2 & $<3$ & 4 & 9 & 2 & 50.0 & 50.0 \\
\hline Mild & 3 & $>4$ & 4 & $>3$ & 1 & 8 & 2 & 50.0 & 50.0 \\
\hline Mild & 3 & $>4$ & 4 & 3 & 2 & 9 & 1 & 100.0 & 0.0 \\
\hline Mild & 3 & $>4$ & 4 & $<3$ & 4 & 11 & 1 & 0.0 & 100.0 \\
\hline Severe & 6 & 1 to 2 & 1 & $>3$ & 1 & 8 & 22 & 90.9 & 9.1 \\
\hline Severe & 6 & 1 to 2 & 1 & 3 & 2 & 9 & 2 & 50.0 & 50.0 \\
\hline Severe & 6 & 1 to 2 & 1 & $<3$ & 4 & 11 & 2 & 0.0 & 100.0 \\
\hline Severe & 6 & 3 to 4 & 2 & $>3$ & 1 & 9 & 16 & 50.0 & 50.0 \\
\hline Severe & 6 & 3 to 4 & 2 & 3 & 2 & 10 & 7 & 0.0 & 100.0 \\
\hline Severe & 6 & 3 to 4 & 2 & $<3$ & 4 & 12 & 14 & 7.1 & 92.9 \\
\hline Severe & 6 & $>4$ & 4 & $>3$ & 1 & 11 & 8 & 12.5 & 87.5 \\
\hline Severe & 6 & $>4$ & 4 & 3 & 2 & 12 & 2 & 0.0 & 100.0 \\
\hline Severe & 6 & $>4$ & 4 & $<3$ & 4 & 14 & 3 & 0.0 & 100.0 \\
\hline
\end{tabular}

Mantel $\mathrm{X}^{2}$ for trend of the association of Total Score and success of Surgical Closure $=183.1, \mathrm{p}<0.001$.

\section{Prognosis Score and Fistula Classification}

\begin{tabular}{cccc}
\hline SCORE & TOTAL CASES & OUTCOMES & OBSERVATIONS \\
\hline $03-05$ & 265 & $90 \%-100 \%$ & Type 1: Simple OF \\
$06-08$ & 65 & $50 \%-90 \%$ & Type 2: Complicated OF \\
$>08$ & 60 & $<50 \%$ & Type 3; Complex OF \\
\hline
\end{tabular}

Total Score $=14$. 
Submit or recommend next manuscript to SCIRP and we will provide best service for you:

Accepting pre-submission inquiries through Email, Facebook, LinkedIn, Twitter, etc. A wide selection of journals (inclusive of 9 subjects, more than 200 journals)

Providing 24-hour high-quality service

User-friendly online submission system

Fair and swift peer-review system

Efficient typesetting and proofreading procedure

Display of the result of downloads and visits, as well as the number of cited articles Maximum dissemination of your research work

Submit your manuscript at: http://papersubmission.scirp.org/

Or contact ojog@scirp.org 